\title{
US Stock Market And Macroeconomic Factors
}

Francisco Jareño, University of Castilla-La Mancha, Spain Loredana Negrut, University of Castilla-La Mancha, Spain

\begin{abstract}
This paper analyzes the relationship between the US stock market and some relevant US macroeconomic factors, such as gross domestic product, the consumer price index, the industrial production index, the unemployment rate and long-term interest rates. All the relevant factors show statistically significant relationships with the stock market except for the consumer price index, and the signs are consistent with the findings of previous literature.
\end{abstract}

Keywords: US Stock Market; US Economy; Macroeconomic Factors; Correlation Analysis

\section{INTRODUCTION}

$\mathscr{T}$ he relationship between the stock market evolution and the real economy is evident, although the direction of the causality relationship is a controversial topic. Nevertheless, most of the previous literature supports the idea that any movement in the stock market has an impact on the main macroeconomic factors and vice versa.

Thus, the relevant aim of this paper is to analyze the relationship between the economic cycle and the evolution of the stock market, that is, the relationship between the financial and real economy.

According to Peiró (1996) and Humpe and Macmillan (2009), the stock market may anticipate economic behavior, such that changes in economic cycles could be related to the volatility of the main stock market indicators.

Figure 1. Economic Cycle and Stock Market Cycle

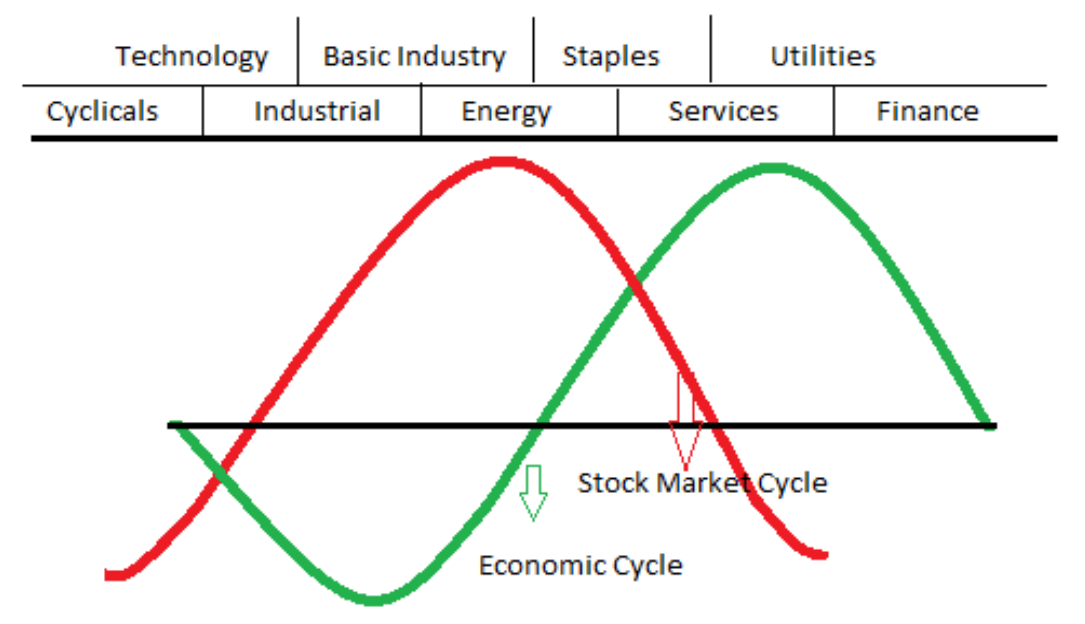

\begin{tabular}{|lll|}
\hline Full Recession $\quad$ Early Recovery $\quad$ Full Recovery $\quad$ Early Recession \\
\hline
\end{tabular}

\begin{tabular}{|lll|}
\hline Market Bottom Bull Market $\quad$ Market Top $\quad$ Bear Market \\
\hline
\end{tabular}

Source: Own preparation based on www.marketoracle.co.uk 
Figure 1 shows the relationship between the stock market of a country and the evolution of the domestic economy (Peiró, 2015). Normally, the stock market moves according to the business cycle — between six and twelve months at a time. Thus, this paper studies the possible effect of the US stock market on relevant US macroeconomic factors, such as gross domestic product, the consumer price index, the industrial production index, the unemployment rate and long-term interest rates.

The remainder of the paper is structured as follows. Section 2 succinctly describes the motivation for the paper, and reviews the historical evolution of the Dow Jones and S\&P500 indices as representative indicators of the US stock market, including some relevant previous literature. Section 3 describes the data and methodology. Section 4 studies the possible relationship between the quarterly performance of the Dow Jones index and certain US macroeconomic factors. Finally, Section 5 summarizes the main conclusions of the paper and proposes future research.

\section{MOTIVATION AND PREVIOUS LITERATURE}

\subsection{Motivation}

The stock market is an essential element of attracting funding for companies or governments directly from investors to support investment projects or increase the size of institutions. The stock market facilitates access to cheaper funding, thus leading to the creation of more jobs and sources, which in turn make products reach the market at lower prices. Hence, the stock market may benefit consumers and help improve the economic conditions of a country.

The main aim of analyzing the US stock market is to investigate whether it truly affects US macroeconomic variables and its potential impact on the economy at the national and global levels.

Indeed, the effect of the US stock market on certain macroeconomic factors is an important issue, and an overview of the relevant context is useful in analyzing the financial economy and its impact on the real economy.

\subsection{The US Stock Market Index}

This section describes the two most important indicators of the New York Stock Exchange for investment purposes, primarily the Dow Jones Industrial Average (created in 1896) and Standard \& Poor's Composite Index (S\&P500, created in 1957).

According to Brealey et al. (2007), when economic agents invest in stocks, they do not know which return they will receive. However, if investors examine the historical evolution of stock market returns, they can obtain reasonable estimates of expected returns in accordance with risks.

The Dow Jones index (DJ) represents the 30 largest companies, known as blue chips, and measures the performance of a portfolio consisting of one share of each company.

S\&P500 is more comprehensive than the Dow Jones given the larger number of important companies included. Nevertheless, although DJ lists only a small portion of these 500 companies, these are the companies with more weight in the country, constituting approximately $80 \%$ of the shares traded each day. Thus, DJ initially appears to be a good indicator of the US stock market.

To analyze this statement in greater depth, this section shows the historical evolution of the DJ and S\&P500 indices (Riascos, 2014) in Figure 2. 
Figure 2. The historical evolution of stock indices: S\&P500 and Dow Jones

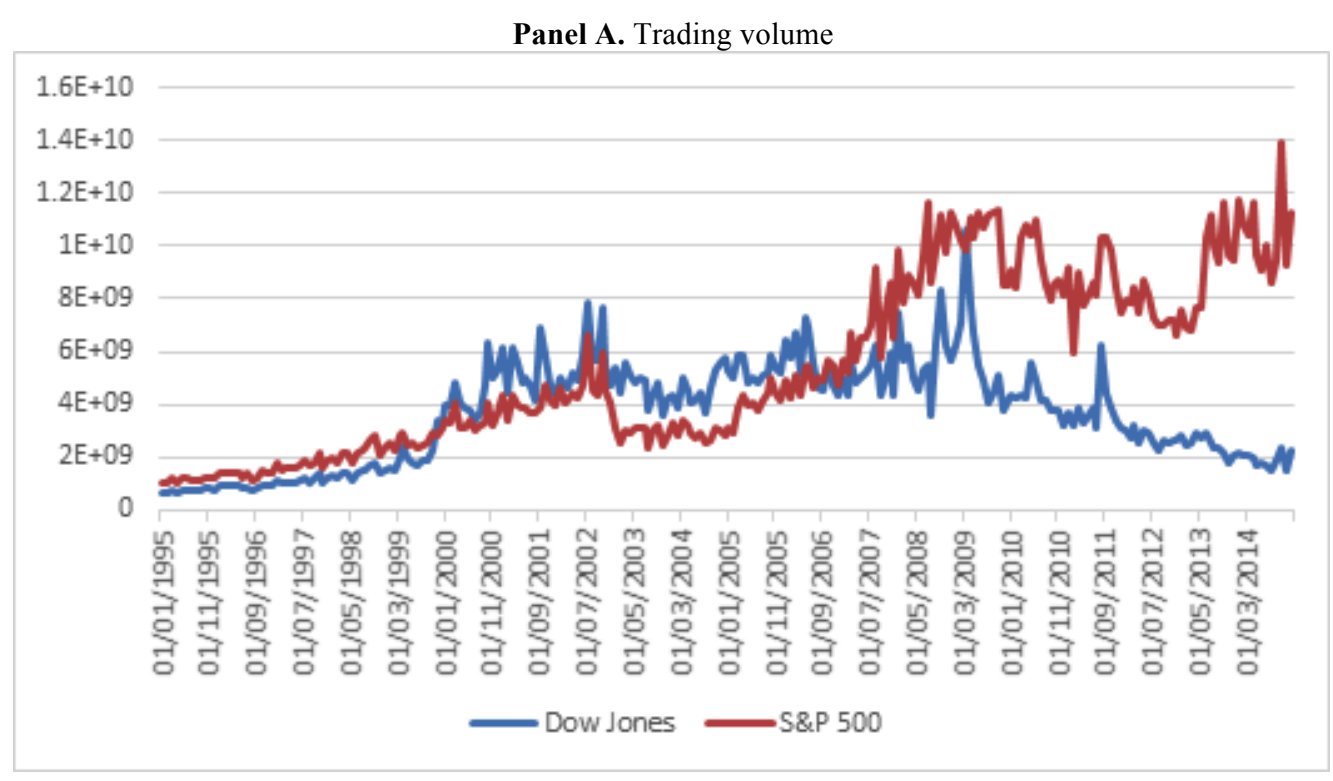

Panel B. Closing prices

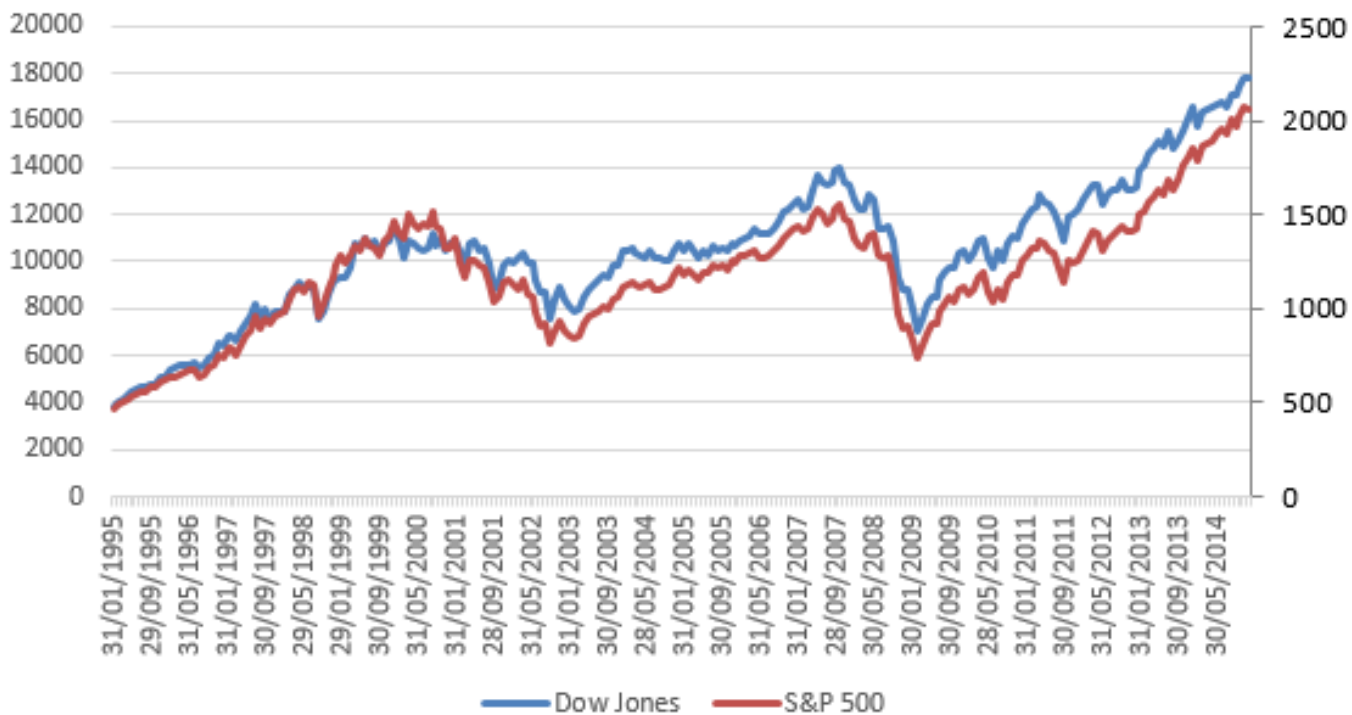

Source: Own preparation from the database www.nyse.com

Panel A of Figure 2 includes the trading volume of the two analyzed indices, showing a very similar evolution. By contrast, panel B of Figure 2 plots the closing prices of both indices using a primary and secondary axis. This panel shows very similar levels for the DJ and S\&P500 indices. Thus, this study selects the DJ index as a simple index that also perfectly reflects the US market evolution.

\subsection{Some Previous Literature}

Is there truly a link between the stock market index and certain macroeconomic factors? Many authors, economists and analysts, such as Rapach et al. (2005), Schwert (1990) and Wasserfallen (1989), have aimed to answer this complex question. They have studied different situations, economic areas and circumstances over time as well as the determinants of balances or imbalances in national and international economies. 
The global economic situation and the future prospects of a country determine the market value of all publicly traded companies. Some empirical facts support the idea that stock prices are fixed in relation to anticipated economic changes. However, there are some criticisms of this perspective, considering the US stock market crash that occurred in October 1987 and affected most world markets, although the economic crisis was not related to clearly identifiable macroeconomic factors.

To analyze this issue, it would be necessary to obtain stock prices and economic activity, but the latter would be more difficult to measure because according to McQueen and Roley (1993), it would be a more complex process that would include variables such as production, employment, commodity prices, interest rates or exchange rates. The prices of shares can be identified through stock indices and are directly related to some of these macroeconomic variables.

Oil prices determine the variation in stock prices, but demonstrating the existence of a relationship between employment and the volatility of stock indices, for example, is much more complex. Higher employment leads to a favorable economic situation that leads to increases in stock prices but may also trigger inflation and higher interest rates that may result in decreases in the value of shares.

All these ideas confirm the complexity of such an analysis and the difficulty in anticipating the expected sign in the relationships to be studied.

As we mentioned at the beginning of this section, many articles investigate the relationship between the stock market and macroeconomic factors. However, they do not find agreement in their conclusions. For example, Rapach et al. (2005), Schwert (1990), Wasserfallen (1989), Chan et al. (1998), Flannery and Protopapadakis (2002) and Maio and Philip (2014) conclude that there is a clear relationship between the stock market and macroeconomic variables, although the signs are unclear in some cases. Authors such as Fischer and Merton (1984) conclude their investigation by claiming that stock returns predict future production. Other economists, such as Fama $(1981,1990)$ and Schwert (1990) confirm the link between the stock market and macroeconomic factors in a country.

In this sense, the works of Peiro (1996), Humpe and Macmillan (2009) and Wasserfallen (1989) analyze the expected signs in terms of the ratio of the stock market to macroeconomic factors, and Table 1 shows the most important results.

Table 1. The relationship between the stock market and macroeconomic variables analyzed: expected signs

\begin{tabular}{lccccc}
\hline & GDP & CPI & IPI & Unemployment & Interest rates \\
\hline Stock Market & Positive & Uncertain & Positive & Negative & Negative \\
\hline Source: Own preparation based on Peiró (1996), Humpe and Macmillan $(2009)$ and Wasserfallen (1989) & &
\end{tabular}

\section{DATA AND METHODOLOGY}

This section proceeds to analyze the different relationships that may exist between the US stock market and suitable macroeconomic factors.

First, the macroeconomic variables used in this research are defined as follows:

- The gross domestic product (GDP) represents the value of all goods and services produced in the United States. This study uses three different measures of GDP: (1) GDP in real terms, (2) the growth rate in percentage, and (3) a seasonally adjusted measure (\%) to obtain more reliable results by eliminating the seasonality of time series data.

- The Consumer Price Index (CPI) is the original data used to obtain the US inflation rate. We have considered this factor as an index and as an inflation rate.

- The Industrial Production Index (IPI) according to the National Statistics Institute is a cyclical indicator that measures the productive activity of the industrial sector (excluding construction). This factor has been considered in the analysis as an index (in levels), and the growth rate (seasonally adjusted) is used as a percentage. 
- The interest rate is the price of money deposited or invested in different business operations. This measure has been included both in levels and in first differences.

- The unemployment rate represents the total number of individuals who are not working but are actively seeking employment.

Specifically, to develop the above analysis, we obtained quarterly data for the 2008-2014 period. Data on the selected macroeconomic variables were obtained from the Eurostat website (http://ec.europa.eu/eurostat) and the National Bureau of Economic Research (http://www.nber.org/). Dow Jones data were obtained from the Yahoo Finance page (http://finance.yahoo.com/).

According to Table 1, based on Peiró (1996), Humpe and Macmillan (2009) and Wasserfallen (1989), a positive relationship between the stock market and both GDP and IPI may be expected. Thus, higher prices in the stock market are associated with higher values for both variables (GDP and IPI), and their behavior proceeds according to the stock market cycle: good news in the financial economy also means good news in the real economy and vice versa. By contrast, the unemployment and interest rates are negatively related to the stock market; that is, higher prices on the DJ index are associated with lower values for these macroeconomic factors, showing anti-cyclical behavior. Again, good news in the financial economy produces good news in the real economy (because these factors, in principle, are better when the values are lower). Moreover, the relationship between the inflation rate and the stock market is uncertain because it can fluctuate according to the needs of the economy.

\section{ANALYSIS OF THE RESULTS}

To support the results of the previous literature, this research uses some progress and scatter graphs to examine the trend in the relationship between stock market prices (in levels) and the selected macroeconomic factors. In addition, we calculated the Pearson correlation coefficients to show whether the relationships found are statistically significant.

\subsection{Graphs That Reflect the Combined Performance of the Stock Market and the Analyzed Macroeconomic Factors and Scatter Plots}

This section charts the aggregated time evolution of DJ prices (market index) and each of the analyzed macroeconomic factors (Figure 3). Additionally, scatter plots are shown in Figure 4. Thus, this research presents the results of the first step in this analysis.

First, we study whether there is a clear relationship between the US stock market and GDP.

Figures 3 and 4 indicate that there is a relationship between GDP and the DJ market index, although it is not conclusive. However, by eliminating the temporary seasonality of this macroeconomic variable, we find a clear positive relationship between the two variables. Furthermore, Figure 3 shows the time lag mentioned in section 1 to show how the Dow Jones increased contributions from the fourth quarter of 2009, while GDP rose from the second quarter of 2010. Therefore, this preliminary analysis may confirm the hypothesis that the stock market is ahead of the economy - that is, the DJ index is ahead of US GDP by approximately 6 months. Hence, the DJ index could be considered a leading indicator of the growth of the real economy.

Second, we address the possible relationship between the stock market and the IPI (in levels and as a percentage growth rate, seasonally adjusted).

In the case of the Industrial Production Index, again, this research can obtain more concrete and reliable conclusions if the seasonality is removed. Therefore, a positive relationship between the Dow Jones index and the IPI may emerge.

Third, we observe the possible relationship between the US stock market and the CPI (expressed as the index and inflation rate). By studying the relationship between the CPI and the Dow Jones index, we find a positive effect. Figure 3 shows that both evolutions have a very similar pattern and close values, which seem to indicate a very strong positive relationship. 
Figure 3. Graphs of the combined evolution of the stock market and macroeconomic factors

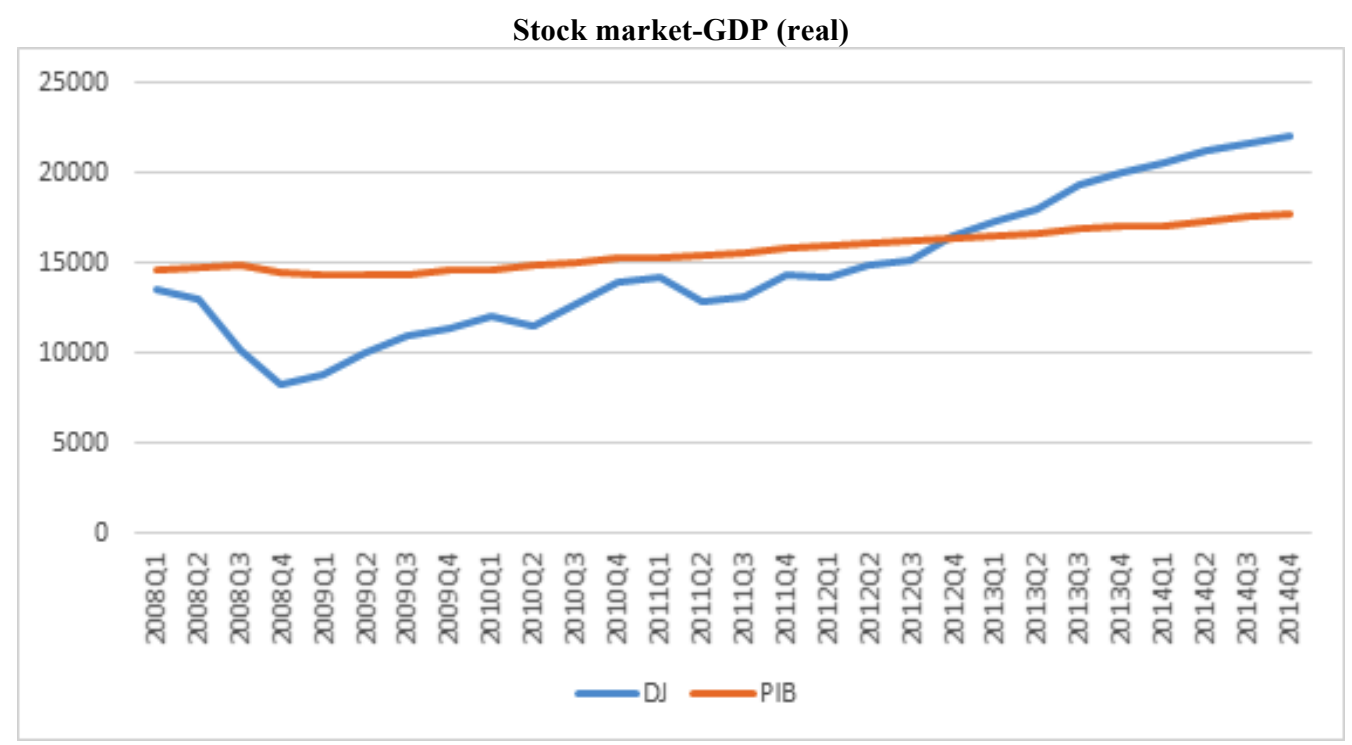

Stock market-GDP (growth rate as a percentage)

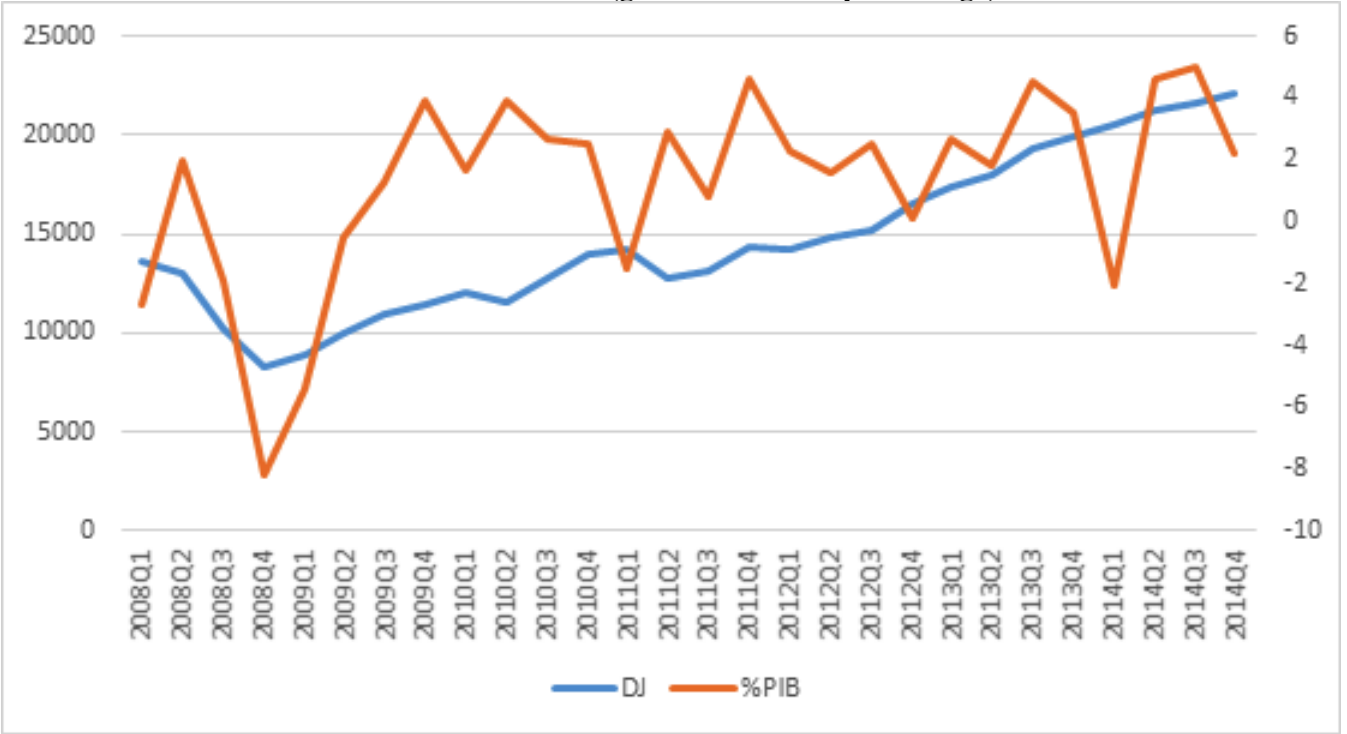


(Figure 3 continued)
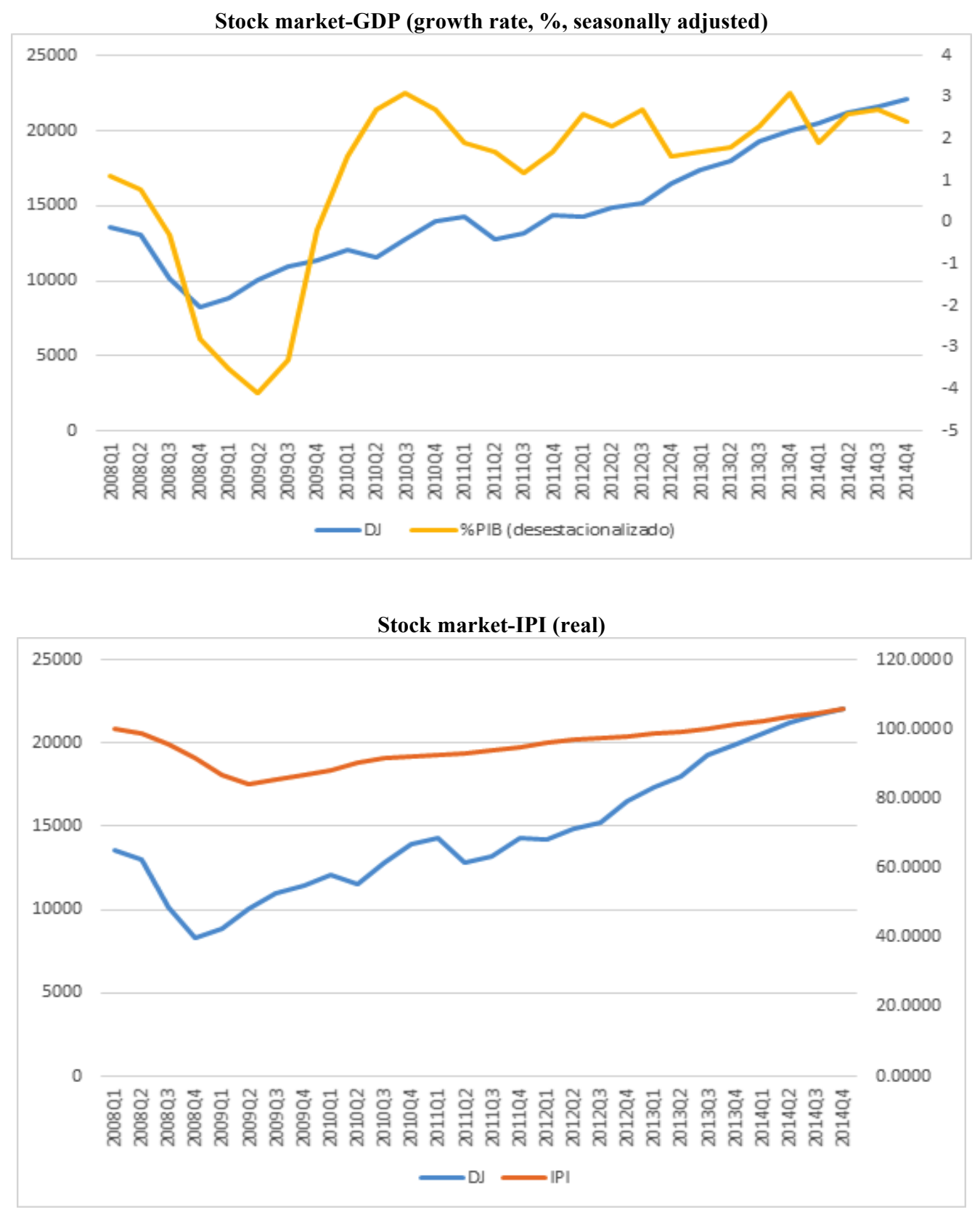
(Figure 3 continued)

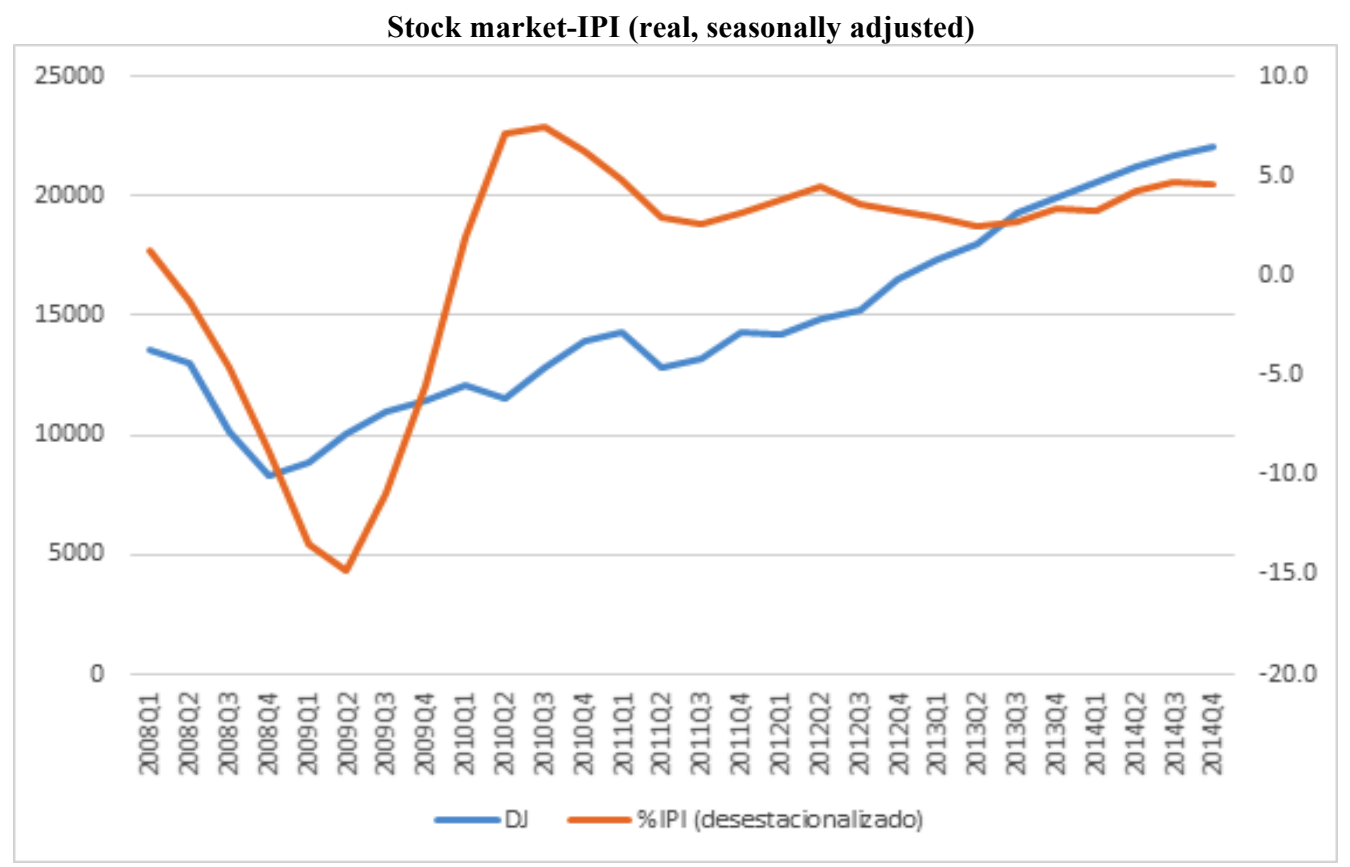

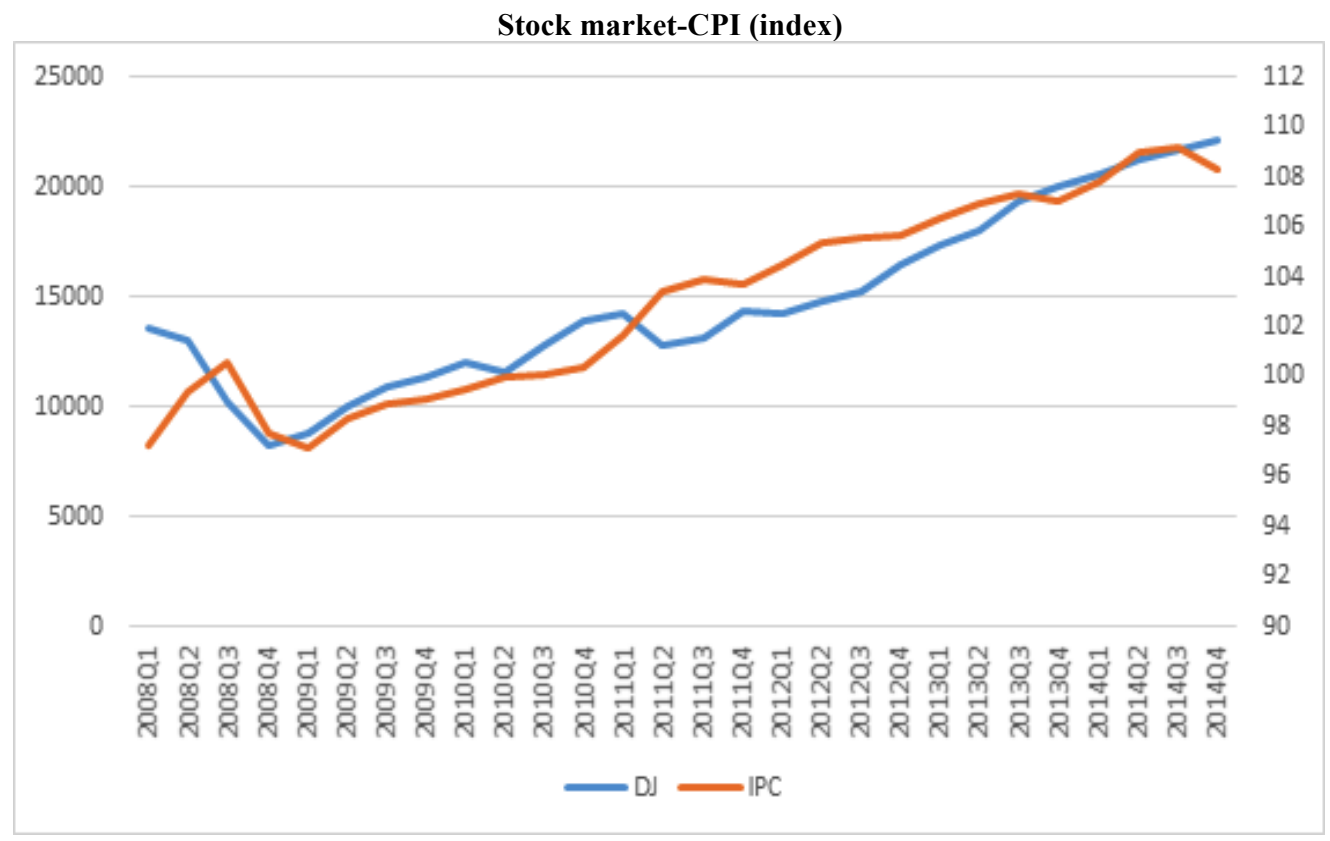


(Figure 3 Continued)
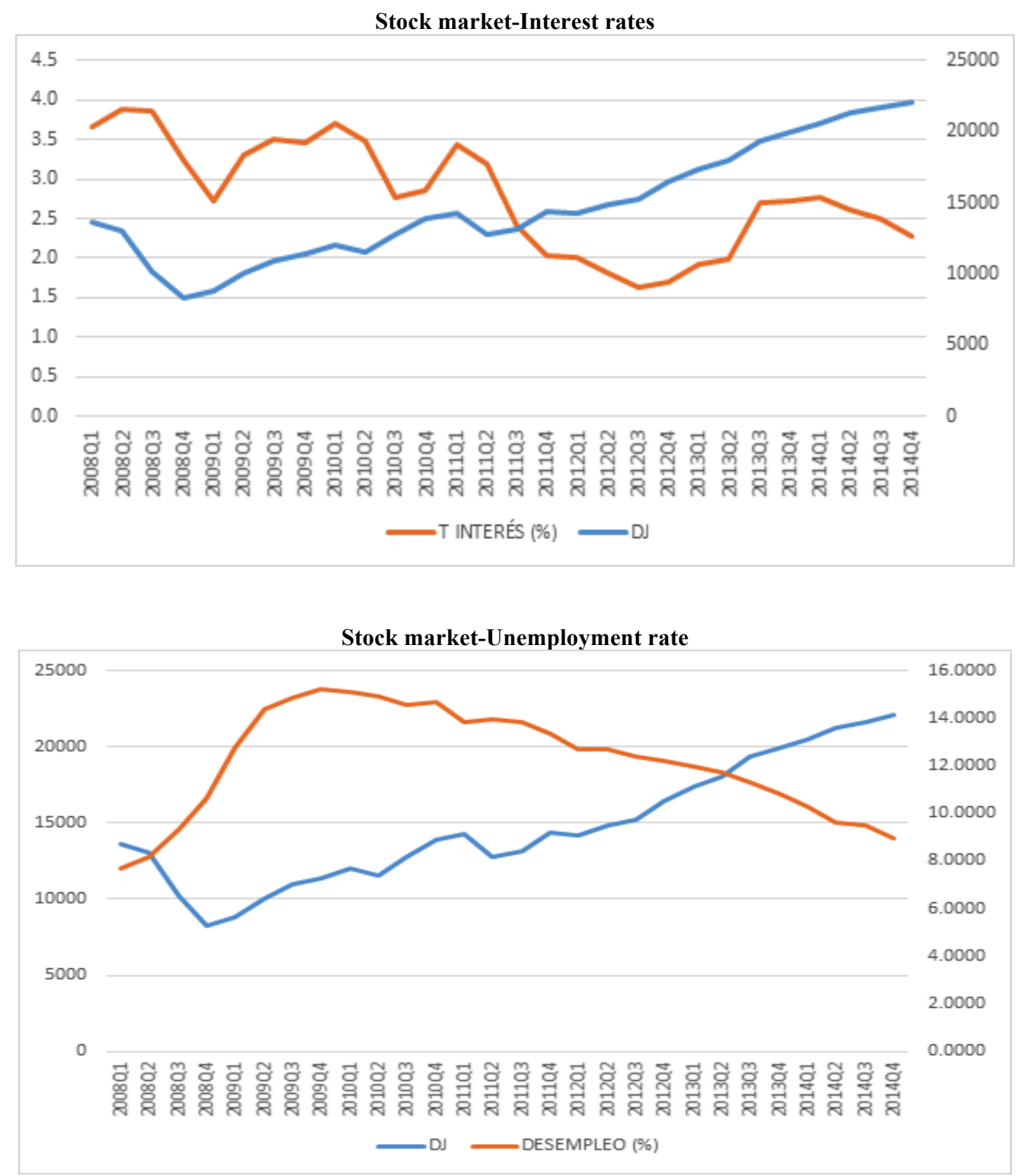

Source: Compiled by the authors from the Eurostat and Yahoo Finance websites 
Figure 4. Scatter graphs with the trend of the stock market and macroeconomic factors

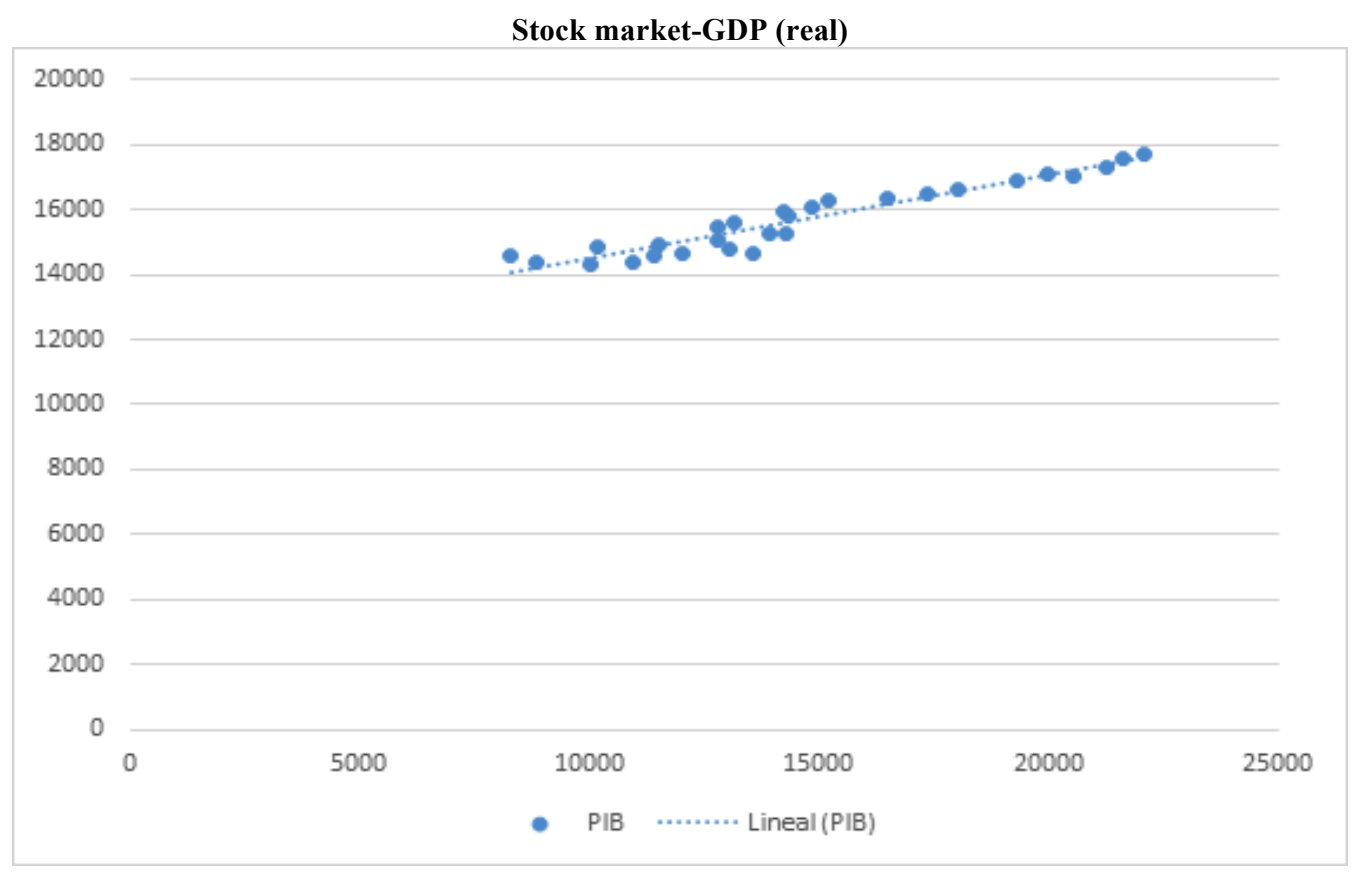

Stock market-GDP (growth rate as a percentage)

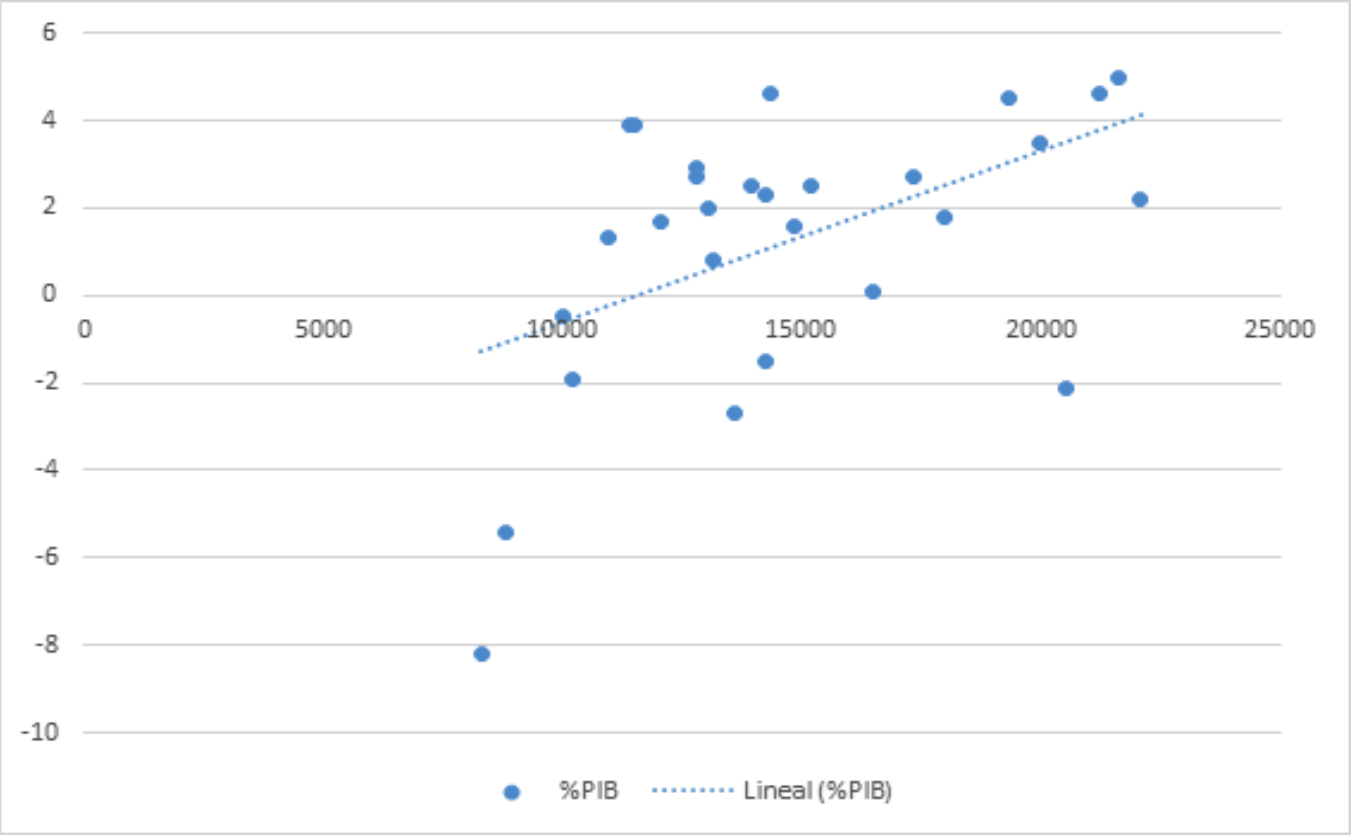


(Figure 4 Continued)

Stock market-GDP (growth rate, \%, seasonally adjusted)

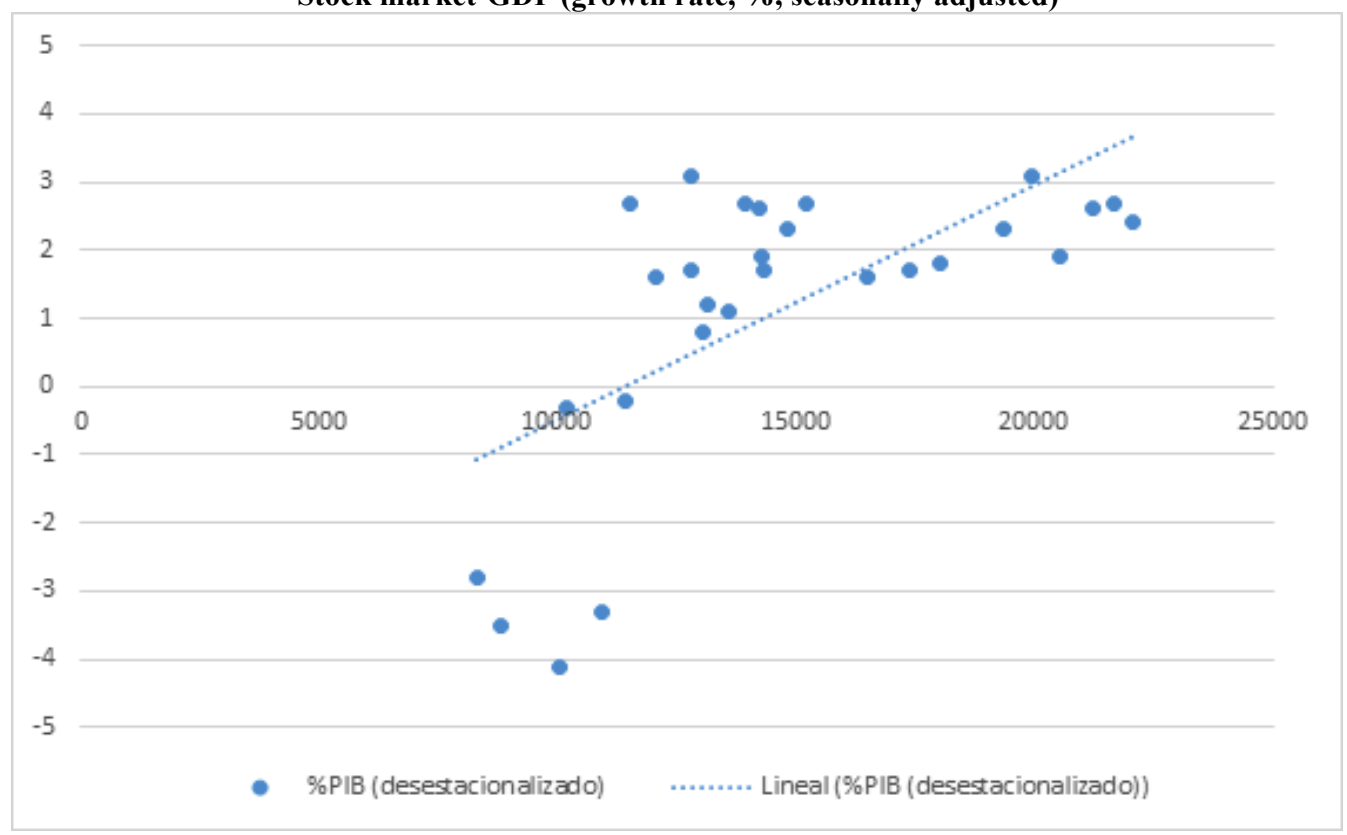

\section{Stock market-IPI (real)}

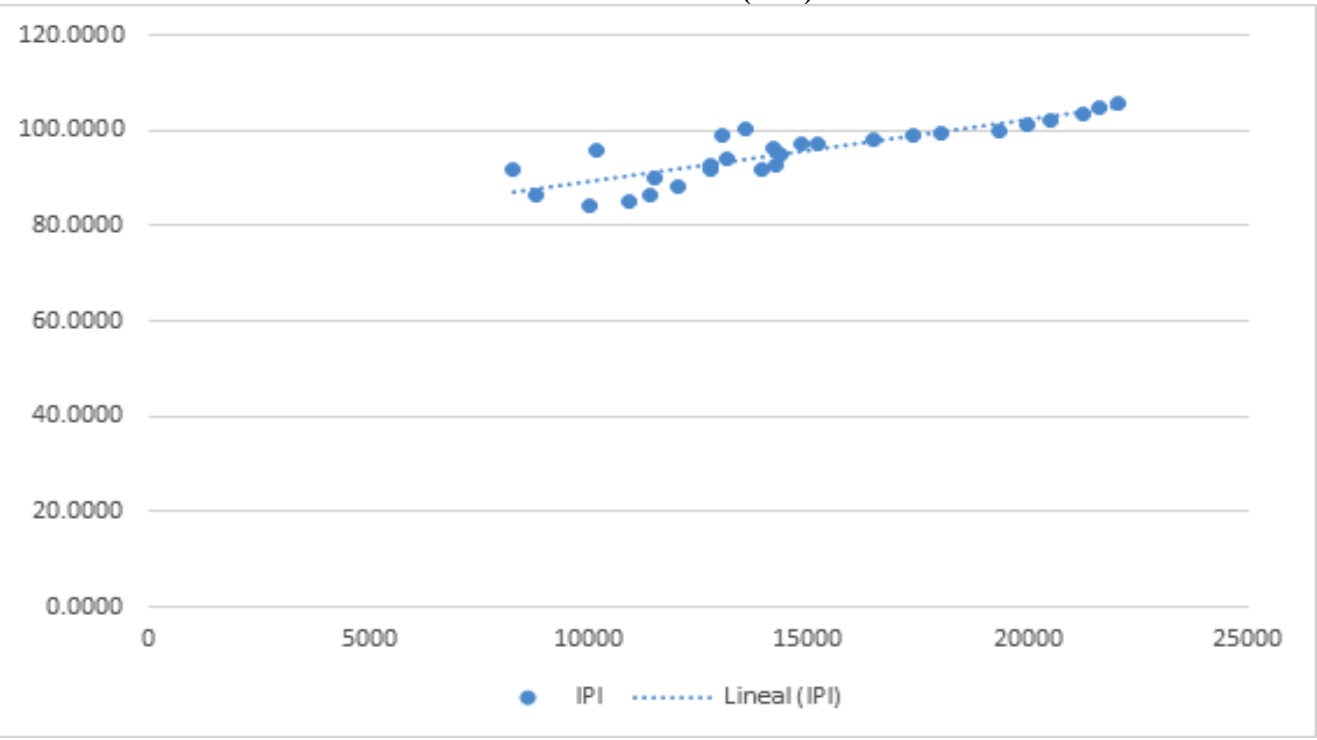


(Figure 4 continued)

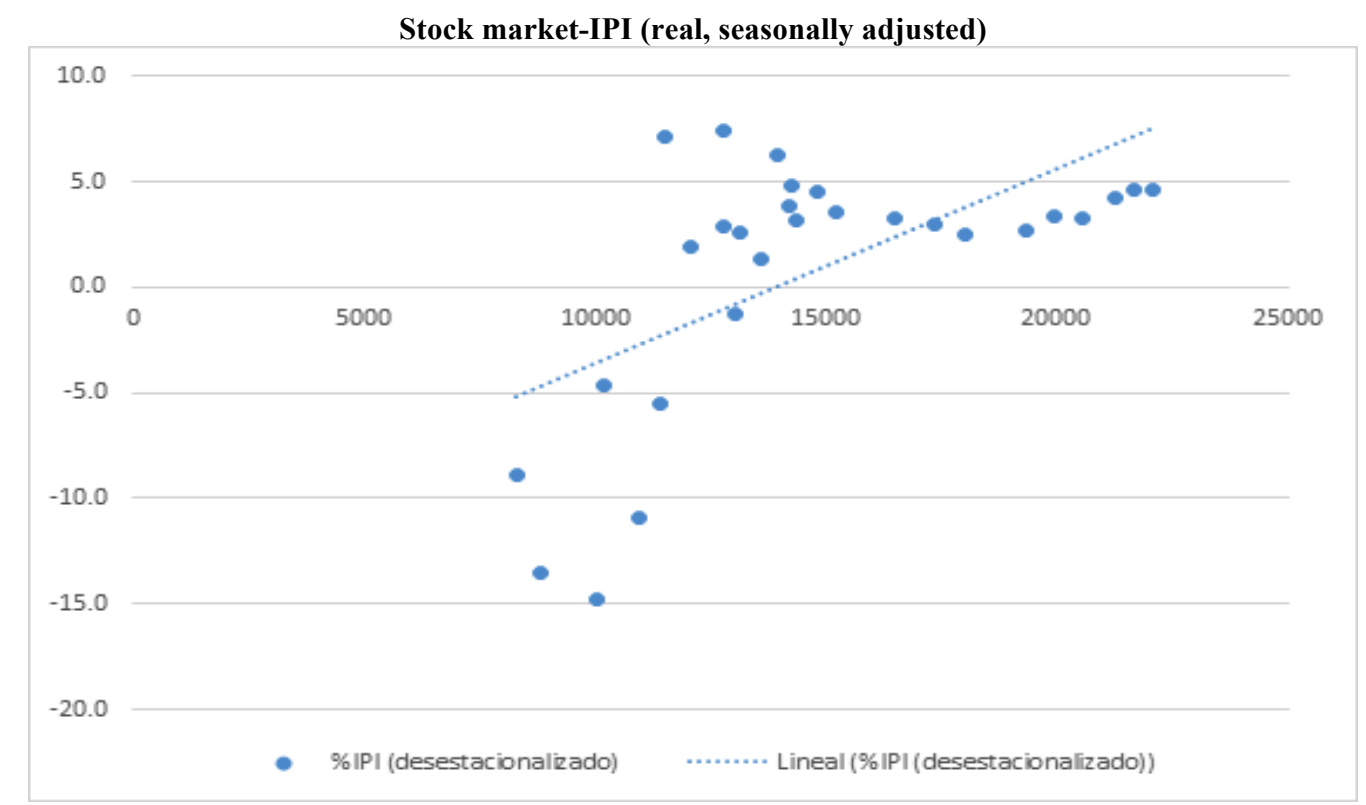

Stock market-CPI (index)

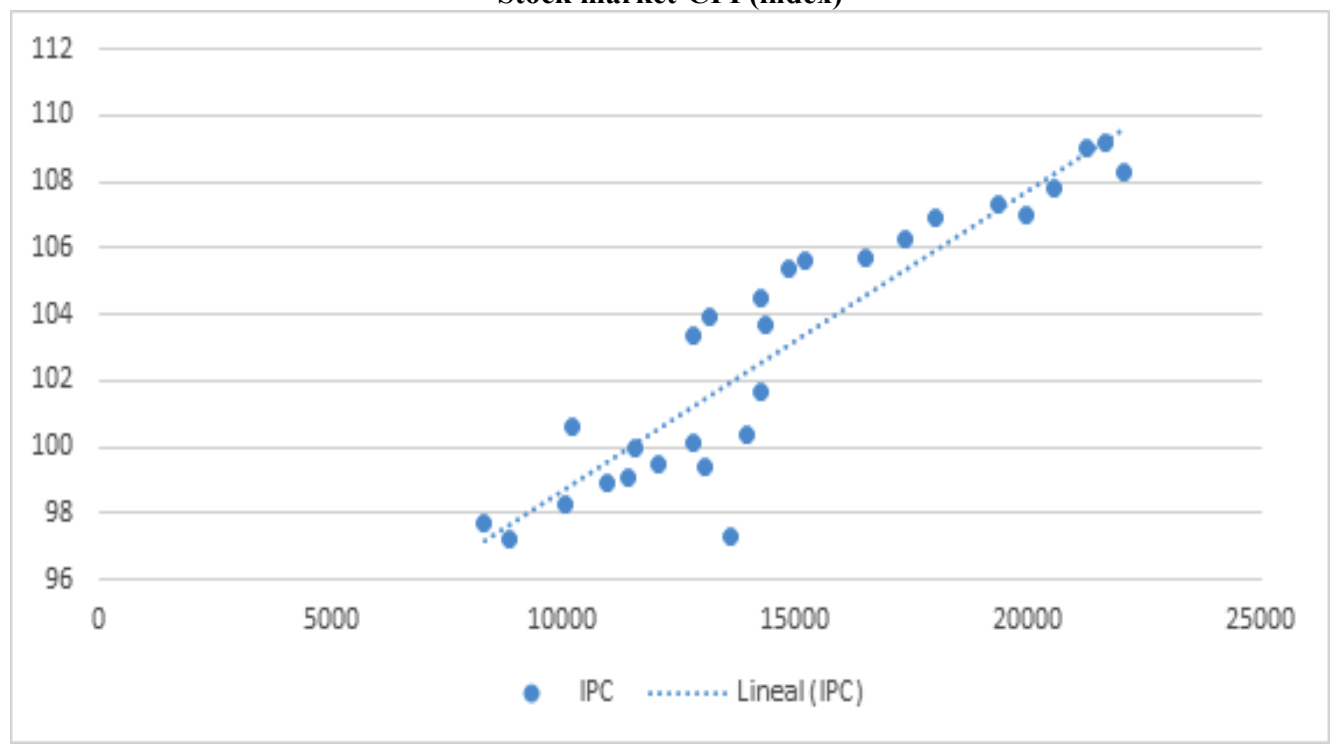


(Figure 4 continued)
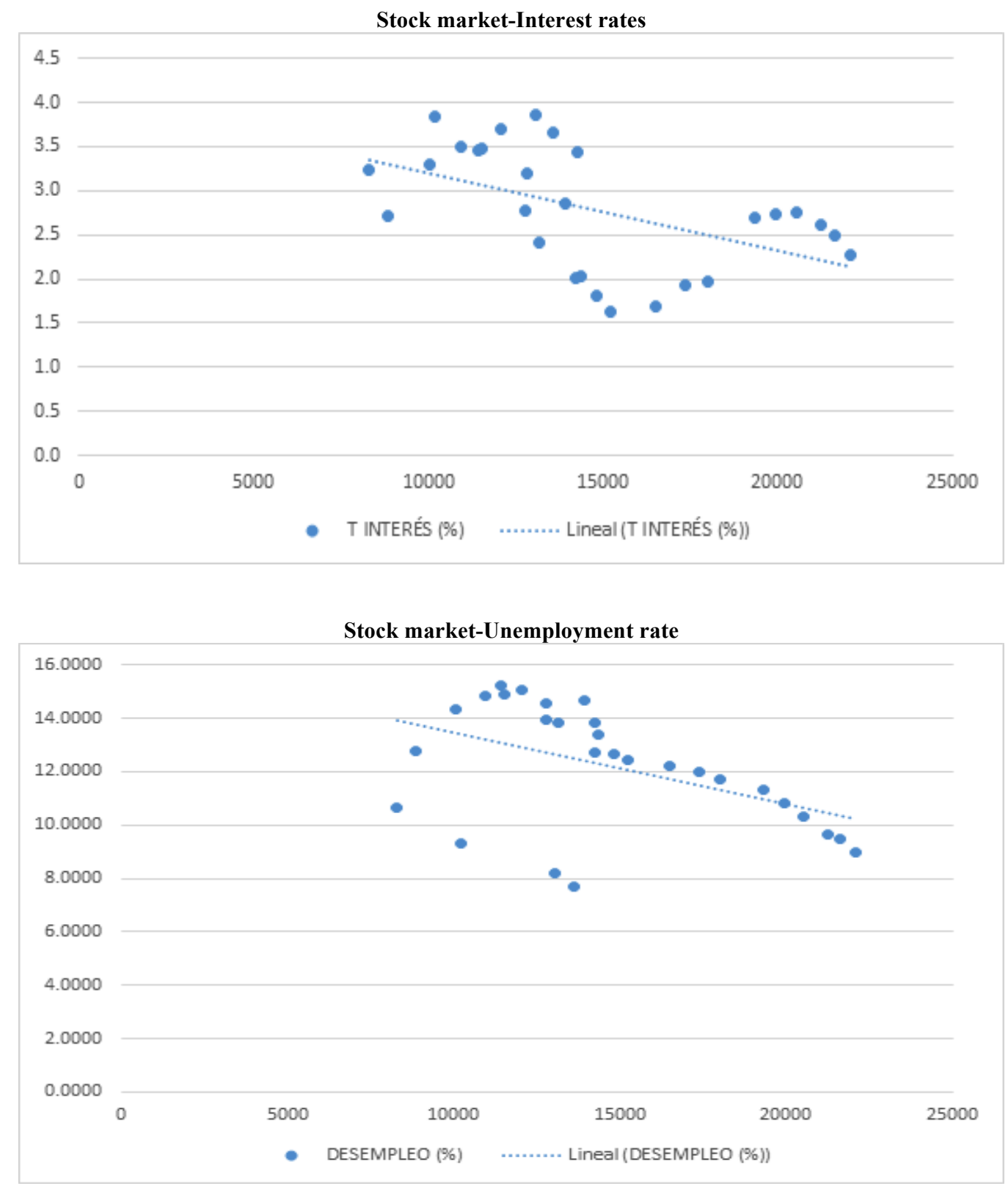

Source: Compiled by the authors from the Eurostat and Yahoo Finance websites

The next relationship analyzed is that between the stock market and the long-term interest rate (in levels and first differences). Figures 3 and 4 exhibit a negative relationship between the Dow Jones index and the interest rate factor. The results show that in the period from the third quarter of 2011 to the second quarter of 2013, the prices of the Dow Jones index increased while the interest rate decreased. By contrast, from the fourth quarter of 2010 to the first quarter of 2011, the interest rate rose while the stock market decreased its quoted prices.

The last relationship studied considers the evolution of the US stock market price and the unemployment rate. This relationship may be negative; therefore, a decrease in US stock market prices could be accompanied by an increase in this economic variable, which would in turn generate a negative scenario for investors and vice versa. 


\subsection{Correlation Matrices Between the Stock Market Price and the Various Macroeconomic Factors}

To complete the investigation, Table 2 presents the correlation matrix to indicate whether the relationships between the stock market index and the analyzed macroeconomic variables are statistically significant.

Thus, Student's t distribution and the associated probabilities (p-value) are used to confirm whether the relationships found are statistically significant.

With regard to the real GDP, the Pearson correlation coefficient between GDP and DJ is positive and very high, with a value of 0.95 . However, the correlation for the growth rate of GDP (\%) and the seasonally adjusted measure (\%) shows low values for real GDP. Thus, there is a direct relationship between the two variables: when the stock market price increases, the GDP also rises. As shown in Table 2, these results are highly statistically significant.

As expected, both for the real IPI and the seasonally adjusted measure (\%), the relationship with the Dow Jones index is positive and statistically significant, although the coefficient values decrease from 0.8647 to 0.6020 . When the Industrial Production Index values increase, the Dow Jones index also changes in the same direction.

In the relationship between the CPI and the Dow Jones index, the results reveal a high Pearson correlation coefficient, which confirms the existence of a positive relationship. Therefore, we can confirm a strong positive correlation between the stock market and the US CPI (index).

Table 2. Correlation matrix between the stock market price and the various macroeconomic factors

\begin{tabular}{|c|c|}
\hline GDP & DJ \\
\hline Real & 0.959616 \\
\hline$t$-statistic & 17.39377 \\
\hline p-value & 0 \\
\hline Growth rate $(\%)$ & 0.499519 \\
\hline$t$-statistic & 2.940146 \\
\hline p-value & 0.0068 \\
\hline Growth rate (\%), seasonally adjusted & 0.65875 \\
\hline$t$-statistic & 4.464581 \\
\hline p-value & 0.0001 \\
\hline \multicolumn{2}{|l|}{ IPI } \\
\hline Real & 0.864763 \\
\hline$t$-statistic & 8.780616 \\
\hline p-value & 0 \\
\hline Real, seasonally adjusted & 0.602064 \\
\hline$t$-statistic & 3.844879 \\
\hline p-value & 0.0007 \\
\hline \multicolumn{2}{|l|}{ CPI } \\
\hline Index & 0.914135 \\
\hline$t$-statistic & 1.149 .746 \\
\hline p-value & 0 \\
\hline \multicolumn{2}{|c|}{ Interest rates } \\
\hline Levels & -0.503071 \\
\hline$t$-statistic & -2.968103 \\
\hline p-value & 0.0064 \\
\hline First differences & 0.198527 \\
\hline$t$-statistic & 1.032851 \\
\hline p-value & 0.3112 \\
\hline \multicolumn{2}{|c|}{ Unemployment rate } \\
\hline Real & -0.465782 \\
\hline$t$-statistic & -2.683957 \\
\hline p-value & 0.0125 \\
\hline
\end{tabular}

Source: Compiled by the authors from the Eurostat and Yahoo Finance websites 
In the latter two cases, both the interest rate and the unemployment rate have negative and statistically significant relationships with the market DJ index. This result can be interpreted as indicating that before these macroeconomic factors decrease in value, the Dow Jones index would experience an increase, which may confirm the evidence obtained in the previous section with the evolution and scatter graphs.

This research on the relationship between the stock market and macroeconomic factors confirms the findings of previous literature.

\section{CONCLUSIONS}

\subsection{Summary and Concluding Remarks}

This work has focused on analyzing the US stock market from the perspective of both the real and financial economy. To do so, this research has analyzed the recent evolution of the main indicators of the US stock market, which are the Dow Jones and S\&P500 indices. In addition, this study has investigated the effect of the American stock market, specifically its evolution, on certain macroeconomic variables.

Thus, after comparing the trading volume and the closing prices of the Dow Jones and S\&P500 index, we surprisingly found that the DJ index (an indicator composed of 30 companies) evolved similar to the S\&P500 in the 2003-2006 period, and they remain at fairly similar levels.

In particular, the hypothesis is that the market can be conceived as a leading indicator of the real economy, as this market index tends to advance the behavior of the economic cycle through a period of six to twelve months. This assumption has been confirmed in this research through the study of the relationship between the Dow Jones market price index and the macroeconomic variables that we analyzed, according to graphs of their evolution and scatter plots.

Furthermore, these relationships have been analyzed from a statistical perspective with the calculation of Pearson correlation coefficients, which show whether these relationships are statistically significant. This analysis shows that the US stock market exhibits a positive and significant relationship with the gross domestic product (GDP) and the IPI (Industrial Production Index) variables and a negative and statistically significant relationship with the unemployment and interest rate variables. Thus, this research confirms the results found in previous studies.

\subsection{Research in Progress}

A possible extension of this research would involve repeating this study using the S\&P500 to represent the US stock market instead of the DJ market index. Thus, it would be interesting to analyze whether there are significant differences in terms of the market index selected.

It would also be interesting to analyze whether the relationships found between the US stock market and macroeconomic variables hold not only with contemporary variables (same period) but also with lags in the study of these relationships. Such a study would indicate whether the US stock market is indeed a leading indicator of the real economy cycle.

\section{ACKNOWLEDGMENTS}

This research was funded by a grant from the "Ramón Areces Foundation public call to bid, 2013", entitled Interest and inflation risk: study of the American stock market.

\section{AUTHOR BIOGRAPHIES}

Francisco Jareño is a professor of finance at Universidad de Castilla-La Mancha, Albacete, Spain. He received a Ph.D. in Economics from UCLM, Spain, and he is interested in term structure of interest rates, term structure of volatilities and risk management. He has been published in high quality international journals. 
Loredana Negrut received a Degree in Economics from Universidad de Castilla-La Mancha, Albacete, Spain. This research is part of her Final Degree Project.

\section{REFERENCES}

Brealey, R., Myers, S.C., and Marcus, A.J. (2007). Fundamentos de Finanzas Corporativas. Madrid: McGraw-Hill.

Chan, L.K.C., Karcesky, J., and Lakonishok, J. (1998). The risk and return from factors. Journal of Financial and Quantitative Analysis, 22: 159-188.

Flannery, M.J., and Protopapadakis, A.A. (2002). Macroeconomic factors do influence aggregate stock returns. Review of Financial Studies, 15: 751-782.

Humpe, A., and Macmillan, P. (2009). Can macroeconomic variables explain long-term stock market movements? A comparison of the US and Japan. Applied Financial Economics, 19: 111-119.

Maio, P., and Philip, D. (2015). Macro variables and the components of stock returns. Forthcoming in Journal of Empirical Finance.

McQueen, G., and Roley, V. V. (1993). Stock prices, news and business conditions. Review of Financial Studies, 6: $683-707$.

Peiró, A. (1996). Stock prices, production and interest rates: comparison of three European countries with the USA. Empirical Economics, 21: 221-234.

Peiró, A. (2015). Stock Prices and Macroeconomic Factors: Some European Evidence. Working paper.

Rapach, D.E., Wohar, M.E., and Rangvid, J. (2005). Macro veriables and international stock return predictability. International Journal of Forecasting, 21: 137-166.

Riascos, C. J. (2014). Riesgo financiero acumulado: el caso de los indices bursátiles de Estados Unidos, 2000-2014. Extracted from http://dialnet.unirioja.es/servlet/articulo?codigo=4820636 [Date of reference: 5 January 2015].

Schwert, G. W. (1990). Stock returns and real activity: a century of evidence. The Journal of Finance, 45: 1237-1257.

Wasserfallen, W. (1989). Macroeconomic news and the stock market: Evidence from Europe. Journal of Banking and Finance, 13: 613-626. 